\title{
Reflexões psicanalíticas acerca dos efeitos da pandemia
}

\author{
Psychoanalytic reflections about the effects of the pandemic
}

\section{Bruna Mello da Fonseca', Elaine Maria Horn' ${ }^{2}$, Fernanda de Souza Gonçalves Dinelli ${ }^{3}$ e Jordan Maia Nunes da Silva}

\begin{abstract}
Resumo: $O$ presente trabalho tem $\mathrm{O}$ intuito de investigar os efeitos subjetivos e sociais causados pela pandemia da Covid-19 e do isolamento social inerente a esta. Para tanto, propomos uma análise do momento atual, dos recursos e da falta de recursos para atravessar este período incerto, o mal-estar gerado pela necessidade de isolar-se, o sofrimento que esta situação ocasiona, as dimensões políticas intrínsecas bem como pretende compreender as repercussões e demandas postas às análises, aos analistas e a psicanálise enquanto método de escuta do inconsciente. Legitimando o desamparo e as angústias proporcionadas pela pandemia, buscamos problematizar os efeitos internos e individuais assim como os efeitos externos e coletivos, sabendo que a psicanálise, enquanto uma ética, pode-se fazer muito importante enquanto dispositivo de escuta, reconhecimento e alteridade. O método utilizado para a produção desse artigo foi alicerçado na revisão da literatura bem como foi enriquecida pelos debates do Comitê de Psicanálise da SPRGS no ano de 2020.
\end{abstract}

Palavras-chave: Pandemia; Isolamento social; Sofrimento.

\begin{abstract}
The present work aims to investigate the subjective and social effects caused by the covid-19 virus pandemic and the social isolation inherent to it. Therefore, we propose an analysis of the current moment, of the resources and the lack of resources to go through this uncertain period, the discomfort generated by the need to isolate, the suffering that this situation causes, the intrinsic political dimensions as well as it intends to understand the repercussions and demands placed on analysis, psychoanalysts and psychoanalysis psychoanalysis as a method of listening to the unconscious. Legitimizing the helplessness and anguish provided by the pandemic, we seek to problematize the internal and individual effects as well as the external and collective effects, knowing that psychoanalysis, as an ethics, can be very important as a device for listening, recognition and otherness. The method used for the production of this article was based on the literature review and was enriched by the debates of the SPRGS Psychoanalysis Committee in 2020.
\end{abstract}

Keywords: Pandemic; Social isolation; Suffering.

\footnotetext{
1 Psicóloga. Psicanalista. Membro efetivo da Sigmund Freud Associação Psicanalítica. Coordenadora do Comitê de Psicanálise da SPRGS. E-mail: bruna.fonsecam@gmail.com

2 Acadêmica de Psicologia. Estagiária em psicologia na SPRGS. Bacharel em Letras e Administração. Pós-graduada em Marketing. E-mail: elainemmelo@gmail.com

3 Acadêmica de Psicologia. Estagiária da SPRGS. E-mail: nanda_172@hotmail.com

4 Acadêmico de Psicologia. Membro da SPRGS. E-mail: jordan.alemanha@gmail.com
} 


\section{Introdução}

A pandemia da Covid-19 interrompe-nos na liquidez do que vivíamos, do mundo acelerado, das relações cada vez mais superficiais, do individual em detrimento ao coletivo. 0 cenário pandêmico obriga-nos a reconhecer a existência do vizinho e, sobretudo, legitimar a importância uns dos outros na vida social. Dependo dos cuidados do meu vizinho - este outro estranho - que também depende de mim. A alteridade se faz imperativa, vem e nos atropela, diz que estar em casa é um ato de amor, de respeito, de humanidade. Como um ato civilizatório, a covid-19 freia a satisfação dos instintos sexuais individuais, barra o sujeito no seu ir e vir, no seu desejo subjetivo, a fim de (re)inscrevê-lo no social, tal como propõe Freud em 0 mal-estar na civilização (1929-1969), onde diz que:

A vida humana em comum só se torna possível quando se reúne uma maioria mais forte do que qualquer indivíduo isolado e que permanece unida contra todos os indivíduos isolados. 0 poder dessa comunidade é então estabelecido como'direito', em oposição ao poder do indivíduo, condenado como'força bruta'. A substituição do poder do indivíduo pelo poder de uma comunidade constitui o passo decisivo da civilização (Freud, 1929-1969, p. 101).

0 momento que vivemos é de recolhimento, de reclusão, de isolamento social ou ainda de manutenção de algo maior em nome da saúde, do bem-estar social, de interesses que vão bem além dos individuais, mas da coletividade, do global. Éo momento do "fique em casa", de manter o devido distanciamento social, de respeitar as regras, usar máscara, limpar as mãos com álcool gel, de não tocar, não beijar, não abraçar, não se aproximar fisicamente do outro. Este outro que tantas vezes me invadia em minha intimidade, em casa, no trabalho, nas ruas. Ao outro agora é permitido desaparecer em si.

Em tempos de alta tecnologia, as relações passaram a ser mais virtuais do que pessoais, uma série de mudanças de paradigmas aconteceram em função do uso de celulares, notebooks, jogos virtuais, canais de Youtube, Instagram, Whatsapp, Telegram, Messenger, em que o Facebook já se tornou um veterano, de relacionamentos por aplicativos, entre os mais conhecidos. As pessoas passaram a serem vistas, assistidas, a convivência passou na maioria das vezes do contato pessoal, olho no olho, a um contato virtualizado.

Assim, o presente artigo surge através de inúmeras questões feitas a partir dos encontros virtuais do Comitê de Psicanálise da Sociedade de Psicologia do Rio Grande do Sul (SPRGS) durante a quarentena. Como grupo que se propõe a estudar a psicanálise em sua dinâmica com o social, em sua relação com o político, tensionamos o momento vigente a fim de responder ou mesmo abrir ainda mais al gumas perguntas. Quais os efeitos subjetivos $\mathrm{e}$ globais causados pela pandemia covid-19? Quais os afetamentos inerentes ao que vivemos? Como dimensionar o impacto emocional causado pela imposição da virtualidade em nossas vidas? Quando falamos sobre o sofrimento suscitado pela pandemia, falamos de algo comum a todos? Como a política se relaciona com as experiências de vida e de morte neste contexto de saúde pública? Equal sua relação com a psicanálise? Como pode a psicanálise, esta ética, encarregar-se subjetiva, social e politicamente de escutar as diferentes dores dos sujeitos? Que transformações cabe ao ofício do psicanalista em tempos de virtualidade e como seguir escutando o inconsciente dos analisan- dos, uma vez que estamos atravessados - todos nós - pela barreira tanto da castração quanto da alteridade esta que nos faz ficar em casa? Para além dos tempos pandêmicos, não seria a alteridade e o registro da castração máximas da psicanálise social? Como efetivá-las?

\section{Método}

0 presente artigo tem como método a revisão literária, bem como os inúmeros debates, exemplos, interlocuções e leituras ocorridos ao longo do Comitê de Psicanálise da Sociedade de Psicologia do Rio Grande do Sul no ano de 2020. No que tange ao desamparo proporcionado pela pandemia, faz-se necessário a busca na literatura por ferramentas, recursos e canais de debate a fim de atravessarmos esse período de incertezas. Sendo assim, foram consultados artigos, livros, lives e vídeos escritos ou gravados por psicanalistas dispostos a (re)pensar a psicanálise bem como as técnicas possíveis para 0 enfrentamento e a permanência das análises em período pandêmico. Da mesma forma, foram feitas consultas bibliográficas a fim de problematizarmos o momento e seus efeitos subjetivos.

\section{Sofrimento em tempos de pandemia}

Ocorre que não estávamos preparados para as mudanças que acabaram sendo impostas em função da pandemia, mudanças de comportamento, de atitudes, de tratamento e de postura diante de si e do outro. Mudanças que impactaram também na liberdade do ir e vir, da mobilidade, da escolha, da possibilidade do encontro e do desencontro.

Desde antes da pandemia, a sobrevivência de Eros está ameaçada pelo domínio do narcisismo, uma vez que em nossa sociedade predomina 0 investimento dos sujeitos apenas e tão somente em si mesmos e em suas demandas, afetando o investimento pulsional no outro e um maior reconhecimento daquilo que versa a respeito de pautas sociais e coletivas. Nesse sentido, existe um desgaste na ideia do outro, uma erosão do outro. Há uma raiz de extremo narcisismo, "narcisificação de si mesmo" em que o outro vai desaparecendo. Estas são ideias apresentadas pelo filósofo Han em seu livro "Agonia de Eros" (2017). No Capítulo 1, Melancolia, percebe-se que 0 amor estaria fadado a desaparecer em tempos atuais, tempos em que 0 amor não tem vez, no pensamento do autor, em que a relação com o outro estaria frente a uma erosão do outro, um desgaste que avança de modo sorrateiro.

Conforme Han (2017), estamos a todo momento comparando tudo e nivelando tudo ao igual, porque perdemos a experiência da atopia do outro e, ousa-se dizer, da utopia do outro. A tendência da sociedade de consumo é eliminar a alteridade atópica em favor do igual, de diferenças consumíveis, heterotópicas. Essas diferenças são uma positividade em contraposição à alteridade. A cultura atual não admite a negatividade do atopos.

No narcisismo constante, a libido é investida na própria subjetividade, ele não consegue perceber o outro. Como possível consequência, Han sugere a leitura da depressão como uma doença narcísica, na qual o sujeito depressivo-narcisista está esgotado e fatigado de si mesmo:

0 sujeito do desempenho depressivo mergulha e se afoga em si mesmo. 0 eros, ao contrário, possibilita uma experiência do outro em sua alteridade, que o resgata de seu inferno narcisista. Ele dá 
curso a uma denegação espontânea do si mesmo, um esvaziamento voluntário do si mesmo. Um sujeito do amor é tomado por um tornar-se fraco todo próprio, que vem acompanhado ao mesmo tempo por um sentimento de fortaleza. Mas esse sentimento não é 0 desempenho próprio de si mesmo, mas o dom do outro. № inferno do igual, a chegada do outro atópico pode tomar uma forma apocalíptica. Aliás, hoje, só um apocalipse nos poderá libertar- sim, redimir- de um inferno do igual em direção ao outro (Han, 2017, p. 2-3).

O sujeito de hoje voltado narcisicamente ao desempenho está em busca de sucesso e bons resultados, o que enreda esse sujeito mais profundamente em seu ego. 0 sujeito do desempenho depressivo mergulha e se afoga em si mesmo.

Neste contexto faz necessário também refletir sobre o cotidiano que cobra um desempenho constante, sobreposição de tarefas, funções, demandas, e, assim, precisa-se apresentar resultados para uma sociedade que não abre espaço para o ser, para o ócio, não permite parar, que não existe sem produtividade. 0 ócio é visto de forma negativa e em tempos de pandemia que deveria ser acatado, acolhido e respeitado, tornou-se um indesejado, um pássaro na gaiola, ente provocador de pensar mudanças, sofrimentos e adaptações. Há outras formas de se lidar com o tempo em momento de pandemia, mas a angústia generalizada quer que se aja como se tudo estivesse igual, embora saiba-se que nada mais está igual. Foi preciso criar a máxima "tudo bem não estar bem", para reconhecer que se pode - e talvez mesmo deve-se - sofrer no cenário que vivemos, para que possamos barrar um pouco o imperativo da produtividade, para que não nos sintamos em casa à toa, esperando a pandemia passar. Colado ao home office, fomos induzidos - por quem mesmo? - a estar e viver no/o trabalho.

Sobreviver a esse momento sem espaço para o ócio gera ainda mais sofrimento, as cobranças adoecem, a desesperança quer tomar seu lugar, a exigência de manter a performance, a competitividade e sempre ótimos resultados ressuscita Ford com outros nomes em diversas roupagens. Os adultos precisam de tempo de espera, as crianças precisam do espaço delas, aos adolescentes é preciso permitir existir e viver assim como aos idosos. Há muito que se pensar a respeito das questões psíquicas, das consequências, dos ajustes e dos sofrimentos atuais em tempos de pandemia, mas é preciso reconhecer que é tempo de espera, é tempo de saber aguardar para que alguns ainda consigam pintar pássaros fora da gaiola, em pleno voo.

Na atual circunstância retomamos a importância e a discriminação de alguns conceitos que se fazem oportunos, tais como mal estar, sofrimento, sintoma, traumático, angústia, entre outros. Conceitos estes que estão vívidos em nosso vocabulário em razão da intensidade de nossos sentimentos. Para tanto, Dunker (2015) em Mal-estar, sofrimento e sintoma aborda os efeitos na contemporaneidade das lógicas diagnósticas. Coloca que estas subordinam-se a dialética medicamentosa, que dá nomes aos padecimentos a fim de que suas curas possam ser compradas, a fim de que, passível de "representação", o sujeito possa pertencer a uma classe de sofrimento. Subordinam-se também às lógicas biopolíticas, às representações de saúde, às argumentações psiquiátricas e normativas. Nesse sentido, entende-se que para além do diagnóstico está a diagnóstica, que propõe a compreensão do sujeito através de uma equação que supera os rótulos e as nomenclaturas enclausurantes. Entende-se aqui o sujeito como biopsicossocial, político, subjetivo, sujeito este do inconsciente, da lacuna. À vista disso, o sujeito só pode ser compreendido em sua complexidade, para além de um fato isolado.

Um exemplo disso se faz oportuno a partir da pandemia. 0 sujeito que sofre não sofre só ou apenas por estar isolado: há que se considerar todo seu repertório psíquico, sua história prévia, suas relações interpessoais, os significantes a que atribui desejo, suas condições financeiras, de trabalho, sua saúde orgânica prévia, sua rede, seu contexto social e político. Em virtude disso, 0 conceito de dor é extremamente singular, não compartilhável, intransferivel. Já o conceito de sofrimento tange a uma experiência "que se partilha e é função direta dos atos de reconhecimento que o determinam como tal" (Dunker, 2015 p. 24), ou seja, há a possibilidade de reconhecermos um determinado sofrimento a que compartilhamos ao cruzarmos o mesmo período pandêmico juntos, ao estarmos isolados, ainda que cada qual com as suas vicissitudes. Dessa forma, o que sentimos é comunitário e também íntimo. Público - 0 sofrimento - e privado - a dor. Mediante estas experiências, al guns produzem sintomas, outros convivem com o mal estar do inominável, da angústia do indizível, do nunca antes vivido. 0 comum, no entanto, é que esta experiência revira no inconsciente todas as montagens psíquicas atribuídas às noções de desamparo, trauma e angústia. 0 mortífero do vírus conecta-se com 0 orgânico em nós, com as experiências primevas já recalcadas e nos suscita o desamparo existencial, inerente a nossa condição humana e desprotegida por excelência. Como não angustiar-se frente ao reconhecimento de que lado a lado a vida está a morte? Somos mais uma vez sacudidos pelo solavanco da castração e da mescla entre vida e morte, entre nosso reconhecimento da realidade em oposição a satisfação. Dor, sofrimento, angústia: concernentes a vida, doa a quem doer.

\section{A não democracia do sofrer}

A pandemia da Covid-19 fora tomada por muitos a partir de uma perspectiva democrática, uma vez que através dessa leitura o vírus não faz distinção social, afeta ricos e pobres, brancos e negros, pessoas de todas as nacionalidades e em todas as condições biopsicossociais. Cabe, todavia, ressaltar que o ponto de partida para a contaminação pelo vírus há que pesar: partimos de realidades diferentes no momento em que al guns contam com saneamento básico, possibilidades de higienizar-se de acordo com as orientações médicas e sanitaristas, moram em casas com estruturas que protegem e resguardam, possuem maior e melhor acesso à saúde, tendo menos comorbidades e estando expostos a um menor número de patologias, gozam de maiores oportunidades de vida e bem estar. 0 mesmo não é válido para outras camadas da população que, por sua vez, moram em condições precárias, muitas vezes dividindo a casa com muitas outras pessoas, tendo que manter seus trabalhos para o sustento mínimo da família, não podendo isolar-se, não partindo dos mesmos recursos de saúde, não tendo o mesmo acesso à informação e à educação quanto aos cuidados advertidos frente à pandemia. É sabido que alguns passam fome enquanto outros têm a possibilidade de seguir exercendo suas profissões aos moldes de home office. Nesse sentido, discorda-se da máxima onde diz que passamos por uma situação democrática. 0 oceano que atravessamos é o mesmo, porém as embarcações que dispomos para enfrentar o mar aberto são diferentes e necessárias de serem levadas em consideração. 
Assim sendo, torna-se imperativo reconhecer que não estamos (mais uma vez) todos juntos nessa e que a tentativa de democratizar o cenário pandêmico opera também a serviço de negar e desmentir diferenças tão evidentes do ponto de vista sociopolítico. Desta forma, pode-se reconhecer a multiplicidade dos afetamentos proporcionados pela pandemia. Há um sofrer que é coletivo, porém não é universal. Acredita-se, aliás, que sofrer nunca é ou será universal, do contrário teríamos forças suficientes para que não sofrêssemos. Com isto, o que se observa é que há um sofrer coletivo inerente a determinados grupos que sentem os efeitos do isolamento de diferentes formas. 0 sofrer de um morador da periferia que tem de sair de casa diariamente e seguir trabalhando para não passar fome é radicalmente distinto do sofrer de um executivo que se vê trabalhando em casa, porém tendo que conciliar isto com os cuidados de seus filhos, estes sem escola, sentindo-se exausto. Nessa perspectiva, não há sofrer menos ou sofrer mais, ambos são legítimos. Porém, há que se tensionar e trazer à tona os recursos e as condições de sobrevivência de cada um.

É inegável o fato que os governantes igualmente podem influenciar nesses aspectos, na medida que muitas dessas catástrofes foram produzidas pelo descaso, pelas políticas de morte e pela construção de verdades descoladas da realidade. Outrossim, há quem defenda posicionamentos políticos de destruição, negacionistas, heterogestores, que dividem as pessoas, muito implicado nas pautas econômicas, pouco interessadas nos impactos destas posições. Minimiza-se, então, os efeitos do vírus, tanto no corpo das pessoas quanto no psiquismo em geral.

Mbembe (2018) em seu livro Necropolítica compreende que a razão éa verdade do sujeito enquanto a política seria o exercício desta razão em âmbito público, vislumbrando um contraste que pressupõe "a instrumentalização generalizada da existência humana e a destruição material de corpos humanos e populações" (p. 10). Versa, assim, sobre as políticas de morte presentes em nossa sociedade e que foram explicitadas através da pandemia covid-19, onde a morte pôde ser banalizada, onde os discursos políticos minimizam os efeitos nocivos e mortíferos da pandemia, tratando-a como uma "gripezinha", reduzindo vidas à números, sujeitos à estatísticas. Dessa forma crua, os discursos não só sustentam o descaso com a vida, como também promovem a morte, instrumentalizando os sujeitos a ignorarem os cuidados consigo e com o outro, potencializando, assim, o nocivo que está para além do contágio do vírus: a falha na castração e na alteridade que tanto mata e fere, desde os registros simbólicos, imaginários e reais.

A tentativa de desmentir a gravidade da situação, aponta para a tamanha perversão, para desumanização tal como para a industrialização da morte (Mbembe, 2018). Para além do vírus, estamos aqui, repetidamente desamparados, inicialmente por nossa condição humana, seguido pelo irrepresentável que vem em forma de contágio e, por fim, mas não menos importante, desamparados pelo Estado que não protege, que não reconhece, que excluí, que marginaliza e que, portanto, mata.

A atual crise sanitária, indiscutivelmente, vem atingindo a todos, de maneira singular sob as mais variadas formas de sofrimentos. Entretanto, a fim de evitar dicotomias, é necessário ressaltar a indissociabilidade que há entre a produção de sintomas e a nossa interação com o laço social. Esta relação pode possibilitar a emancipação dos sujeitos em determinados momentos e em outros ser uma ferramenta utilizada na produção de relações desiguais e práticas segregatórias. Em vista disso, convida-se a problematizar o cenário brasileiro atual, no que se refere às políticas públicas de atenção psicossocial durante este período, bem como o modo de enfrentamento adotado pelo Estado brasileiro. De fato, historicamente, o Estado brasileiro nunca precisou de uma guerra declarada para se voltar contra o próprio povo (Safatle, 2020). Nesse sentido, a pandemia veio a calhar com a tradição colonial desigual que ainda reverbera no imaginário do nosso país. Trata-se, assim, de uma falha estrutural que precede e culmina no mortífero, no nefasto. É como se, dessa forma, algumas estruturas fossem criadas e fundamentadas de modo a sucumbir ao descaso do olhar do(s) outro(s) - o Estado como um grande outro -, a perecerem diante do não reconhecimento de sua existência, da não legitimação do existir.

Dessarte, este cenário calamitoso clama por práticas mais solidárias por parte das autoridades, a fim de reparar minimamente 0 abismo social que vem se estabelecendo. Até o momento, a crise sanitária está sendo pretexto para que o ódio, a ganância e a ignorância de muitos governantes se voltem para própria população, sobretudo as minorias desassistidas (Harari, 2020).

\section{Ser e estar em virtualidade}

Esse novo tempo nos convoca para uma ressignificação das relações, como proposto por Dunker (2018) em seu livro Reinvenção da intimidade. Pensando a partir das teorizações do autor e trazendo-as para o contexto de pandemia, faz-se necessário deslocar as relações interpessoais para a virtualidade em virtude do isolamento e esse movimento traz inúmeras consequências, tais como o sentimento de solidão, o vazio, a adição às tecnologias, sensação de insuficiência - posto que nas redes sociais o que vemos muitas vezes é a grama verde do vizinho -, esgotamento no trabalho e nos estudos. A virtualidade exige também uma distinção entre o que é público e privado e neste momento, também, escancara aquilo de que somos privados. Não à toa as redes sociais têm trazido a marca da nostalgia, do saudosismo através de lembranças, através de hashtags como \#tbt (em tradução literal, de volta à quinta), onde os usuários pedem a volta de momentos vividos, relembram experiências que já se foram.

Nesse sentido, a virtualidade é marcada pela aproximação e distanciamento: ao mesmo tempo em que é o terreno através do qual segue-se trabalhando e buscando as relações interpessoais, é também lugar de cansaço. Após um dia de trabalho em frente às telas, após conectar-se com seus entes queridos a fim de interações e notícias, o sujeito sente-se esgotado, por vezes precisando também ir ao extremo de isolar-se dentro de seu isolamento social. É lícito dizer que a experiência da virtualidade em tempos de pandemia têm sido sentida por cada um de forma subjetiva, de acordo com suas relações prévias com tais meio de comunicação, bem como é sentida através dos recursos disponíveis a cada um em seu íntimo. Cabe, contudo, estarmos atentos quanto aos possíveis efeitos deixados pela necessidade da virtualidade e consequentemente a pandemia.

Outro ponto que se torna evidente através da pandemia é a necessidade que temos de cultura. Como sinalizado no início destas reflexões, enfatiza-se aqui novamente a importância de Eros, no que tange ao caminho da pulsão e suas satisfações. Freud em O mal-estar na civilização (1929-1969) trabalhou o papel e a importância da cultura enquanto processo civilizatório, onde o homem abre mão de gozar livremente de seus instintos sexuais em prol do coletivo, a fim de pertencer, sobreviver, em suma, de ser amado. É um movimento de abandono do narcisismo primário para ter um lugar no social, no discurso e no olhar do outro. Dessa forma, o que vemos na contemporaneidade que se isola é a marca 
da cultura e sua fundamental importância. Na reinvenção dos sujeitos necessária aos nossos tempos, a cultura fez-se necessária: tivemos as lives onde seguimos consumindo nossas fontes de entretenimento e conhecimento, ouvimos músicas, palestras, passamos a assistir mais filmes, séries, consumir mais telejornais, recebemos livros em nossas casas, fomos atrás das quase obsoletas revistas. Em nossa solidão, reinventamos as formas de prazer e satisfação a partir das produções da cultura. Numa sociedade onde consumir cultura éalgo caro, para poucos, destino possível àqueles que gozam de maior privilégio social, a necessidade de cultura escancara ser este um direito também básico.

\section{A psicanálise, seu papel e a virtualidade}

À psicanálise e aos psicanalistas frente à pandemia, também coube reinventar-se. Todas as mudanças de setting inerentes aos atendimentos virtuais ou mesmo a escolha feita por alguns de não iniciarem os atendimentos de forma online, apontam para uma necessidade do psicanalista de encontrar grupos onde o debate possa se amparar. Inúmeros foram os espaços criados para que se pudesse pensar coletivamente o papel da psicanálise diante do isolamento bem como pensar as possibilidades no que tange às análises. Esteve também o psicanalista desamparado diante de um não saber, tal como é próprio a ser psicanalista terminável e interminavelmente: viver com a consigna do desvelar. Contudo, o encontro com pares, ainda que na virtualidade, proporcionou ao psicanalista uma troca de não saberes que permitiu com que os espaços de análise e de produção teórica pudessem ser sustentados. Assim, muitos artigos com esta temática foram produzidos, muitos relatos de experiência foram compartilhados, muitas lives foram feitas a fim de tornar públicos alguns questionamentos. Coube a todos revisitar a ética da psicanálise para que fosse possível decidir se, como e de que forma continuar com a escuta neste novo tempo. Conforme notado por Vertzman e Romão-Dias (2020), diversos analistas ainda não haviam tido a experiência do atendimento via telas e entendem que muitos destes analistas:

[...] se viram diante de um redemoinho que os puxou para um mundo desconhecido. 0 extremo cansaço relatado por muitos de nossos colegas depois de uma jornada de trabalho na nova configuração e as incertezas que passaram a povoar nossos corações e mentes a partir de então, são apenas pequenos indícios das mudanças psíquicas tornadas necessárias para fazer frente a uma realidade que nenhum de nós viveu sem surpresa e abatimento. (Vertzman e Romão-Dias, 2020, p. 270).

Nesse sentido, retoma-se a leitura de Ferenczi (1928-1992) em a Elasticidade da técnica. Nesta obra, Ferenczi (1928-1992), que escutava diversos analisandos não-neuróticos, ocupa-se de pensar em vias facilitadoras à escuta do inconsciente de sujeitos cuja constelação psíquica apresenta al guma falha precoce, cujo aparelho psíquico se formou com significativas faltas. A partir disso, Ferenczi (19281992) convoca os psicanalistas a re-pensarem a técnica psicanalítica e propõe o inconsciente do analista como um instrumento de escuta. Aponta a possibilidade de sentir com (tato) é, através dessa faculdade do sentir, entende que há uma mudança no posicionamento do analista para com seus analisandos bem como para com as análises em si, fazendo uma nova leitura da ética psicanalítica. Indica que: "a confiança em nossas teorias só pode ser condicional, pois 0 caso em questão talvez seja a famosa exceção da regra, ou talvez a necessidade de se modificar algo na teoria em vigor até então. (...) A modéstia do analista não é pois uma atitude que se aprenda, mas a expressão da aceitação dos limites do nosso saber" (p. 36).

Assim sendo, neste momento de desamparo e incerteza que vivemos ao psicanalista é requerido uma maior maleabilidade - mantendo, por excelência, o método -, mas propondo-se a revisitar sua técnica e reinventar-se.

Também o desamparo fora sentido pelos pacientes, que num primeiro momento viveram conosco o estranhamento da virtualidade. Ainda que a psicanálise em seu método seja sustentada pelo não olhar proporcionado pelo divã, a experiência do atendimento virtual difere da experimentada no compartilhar de um espaço, na presença do corpo, dos gestos e, sobretudo, na/da presença física do analista. Os efeitos disso ainda não puderam ser medidos - aqui para além da via transferencial. Acredita-se, todavia, que diversos estudos virão e que nos responderão muitos dos questionamentos que fizemos entre pares. Apesar de possível, há que se reconhecer as incontáveis diferenças de uma análise presencial e de uma que é feita através dispositivos on-line e o que para muitos fora uma dificuldade de adaptação, para outros transcorreu e assentou bem em sua prática. Entende-se que aqui não se trata de certo ou errado, de legítimo ou adaptado: mais uma vez na história da psicanálise, trata-se de um efeito abstrato, vivido de modo muito particular por cada analista e por cada analisando.

Além disso, torna-se também necessário ao psicanalista ocupar-se dos fenômenos sociais ocasionados pela pandemia, pelo isolamento e pelo mortífero que acompanha vividamente este cenário. Dessa forma, devemos estar ainda mais atentos aos sintomas, mal estares e sofrimentos produzidos nesta perspectiva, cabendo, assim, ao psicanalista ocupar-se também do social e do coletivo (mais uma vez). Para além da escuta de nossos analisandos, há um sofrimento que é inerente às privações do momento e que leva a indagações como: qual é o papel e o alcance do psicanalista na atual conjuntura? 0 que é possível escutar de nosso mundo diante desta circunstância? Qual nosso papel frente aos discursos políticos levantados atualmente? Como agentes de saúde mental, como nosso trabalho pode fazer frente e ser potente em tempos tão mortais? Seguimos criando perguntas e hipóteses a partir de nossas escutas diárias do inconsciente.

\section{Considerações finais}

A pandemia nos pegou de surpresa e atingiu em cheio nosso ego, prepotência, em nossas utopias cotidianas. Nossa vida precisou ser restringida nas mais diferentes esferas e nos colocou obstáculos difíceis de serem contornados, falando-se não mais no "quando tudo voltar ao normal", pressupondo um novo mundo, novas formas de nos relacionarmos uns com os outros, bem como com o mundo. Ficamos frente a frente a vários monstros internos que assolam nosso convívio em sociedade desde que o mundo é mundo, o que exigiu que enfrentássemos os nossos próprios medos diante de um desconhecido que pode atingir a todos. Vimos que as diferenças sociais intensificaram-se à medida que as pessoas mais vulneráveis precisaram colocar-se em risco em função de manter a sua própria sobrevivência, enquanto os mais ricos puderam lançar mão de todos os cuidados necessários para manter-se. Presenciamos 
milhares e milhares de pessoas morrendo em um curtíssimo espaço de tempo e sentimos nosso sentimento de incapacidade, impotência, desamparo diante da morte aflorar como nunca.

Este cenário impôs que nos reinventássemos e recriássemos mais uma vez, novas possibilidades. No isolamento de nosso lar, vimos a perspectiva da comunicação através do virtual, paramos para apreciar músicas, filmes, diferentes formas de arte e consumimos cultura. Tivemos a oportunidade de revisitar outras fontes de prazer e satisfação além do convívio social. Obrigados a parar, podemos viver um momento de reflexão sobre a vida e pudemos olhar pela janela de uma forma diferente. A Psicanálise, também, mais uma vez precisou recriar-se. 0 estranhamento e o desamparo causados pela distância deram lugar a um novo flexível que nos possibilitou outro meio de continuarmos cuidando de nosso ser e assim nos adaptando dentro do possível.

\section{Referências}

Han, B-C. (2017). Agonia de Eros. Editora Vozes: São Paulo.

Dunker, C. I. L. (2018). Reinvenção da intimidade. Ubu Editora: São Paulo.

Dunker, C. I. L. (2015). Mal-estar, sofrimento e sintoma: uma psicopatologia do Brasil entre muros. Boitempo Editorial: São Paulo.

Ferenczi, S. (1928-1992). Elasticidade da técnica psicanalítica. Obras Completas, Ed. Martins Fontes.

Freud, S. (1929-1969). O mal-estarna civilização. Editora Imago: Rio de Janeiro. Harari, Y. N. (2020) "Maior perigo não éo virus, mas ódio, ganância e ignorância". Entrevista DW Brasil. recuperado em: https://www.dw.com/pt-br/ yuval-noah-harari-maior-perigo

Mbembe, A. (2018). Necropolititica. Editora n-1 Edições: São Paulo.

Mota, A.; Teixeira, C. (2020) 0 desmonte da Politica Nacional de Saúde Mental em tempos de pandemia. recuperado em: http://www.analisepoliticaemsaude.org/oaps/documentos/pensamentos/debatesepensamentos-saudementalnapandemia/

Safatle, V. (2020) Bem-vindo ao Estado suicidário. Recuperado em https:// jornalggn.com.br/blog/doney/bem-vindo-ao-estado-suicidario-por-vladimir-safatle-n-1-edicoes/

Verztman, J. \& Romão-Dias, D. (2020). Catástrofe, luto e esperança: o trabalho psicanalítico na pandemia de COVID-19. Revista Latinoamericana de Psicopatologia Fundamental, 23(2), 269-290. https://doi.org/10.1590/ 1415-4714.2020v23n2p269.7 